\title{
Pharmacologic therapies for the low cardiac output syndrome in children after cardiac surgery: evidence of their efficacy and trends in their use
}

\author{
Raj Sahulee, Jaclyn McKinstry \\ Department of Pediatrics, Division of Cardiology, NYU Grossman School of Medicine, New York, NY 10019, USA. \\ Correspondence to: Dr. Raj Sahulee, Department of Pediatrics, Division of Cardiology, NYU Grossman School of Medicine, $403 \mathrm{E}$ \\ 34th St, Rivergate B-406, New York, NY 10019, USA. E-mail: Raj.Sahulee@nyumc.org \\ How to cite this article: Sahulee R, McKinstry J. Pharmacologic therapies for the low cardiac output syndrome in children after \\ cardiac surgery: evidence of their efficacy and trends in their use. Vessel Plus 2022;6:5. https://dx.doi.org/10.20517/2574- \\ 1209.2021 .94
}

Received: 2 Jul 2021 First Decision: 19 Aug 2021 Revised: 26 Aug 2021 Accepted: 17 Sep 2021 Published: 6 Jan 2022

Academic Editors: P. Syamasundar Rao, Alexander D. Verin Copy Editor: Yue-Yue Zhang Production Editor: Yue-Yue Zhang

\begin{abstract}
The low cardiac output syndrome describes the phenomenon of the reduction of cardiac output that can occur following cardiac surgery requiring cardiopulmonary bypass. If unrecognized or untreated, this condition can result in significant morbidity and mortality. Along with non-pharmacologic therapies, pharmacologic agents used to help manage the low cardiac output syndrome include catecholamine inotropes, inodilators, systemic vasodilators, pulmonary vasodilators, and other classes of medications. We summarize the rationale and key evidence supporting the use of these therapies in children. In addition, utilizing provider surveys and registry reviews, we describe the current trends in the use of these medications and the variation demonstrated between providers and centers. Given the heterogeneous etiology of low cardiac output syndrome, successful management requires that pharmacologic therapies be tailored to the physiologic derangements of each patient.
\end{abstract}

Keywords: Cardiac surgery, low cardiac output syndrome, pediatrics, cardiac critical care

\section{INTRODUCTION}

The low cardiac output syndrome (LCOS) is generally described as the self-limited reduction of cardiac output that can occur in the first $24 \mathrm{~h}$ after cardiac surgeries requiring cardiopulmonary bypass (CPB). Although there is no strict, unified definition, the phenomenon is well recognized and described. The result 
is an imbalance of oxygen delivery and oxygen consumption at the cellular level that may lead to oxygen debt and organ dysfunction. If unrecognized or untreated, this condition can result in significant morbidity and mortality ${ }^{[1]}$.

Along with considerable advances in cardiac surgery and CPB over the past decades, the prevention and management of LCOS have evolved to include a vast array of pharmacologic and non-pharmacologic strategies to restore the balance between oxygen delivery and demand. Pharmacologic therapies for LCOS have generally included catecholamine inotropes, inodilators, and systemic vasodilators. In addition, various other medications have been used to manage LCOS in the postoperative period but are less commonly used. Finally, for medically refractory LCOS, mechanical circulatory support can be deployed. In this review for Vessel Plus, we hope to summarize high-level evidence (randomized control trials, metaanalyses, systematic reviews) supporting the use of these pharmacologic therapies to manage LCOS and to utilize extensive surveys and registry reviews to describe current trends in their use.

\section{Pathophysiology}

The LCOS is the result of multiple pathophysiologic processes that complicate cardiac surgery requiring $\mathrm{CPB}$. Individual patient characteristics, pre-operative state, intraoperative management, residual anatomic lesions, abnormalities in rhythm, and the inherent inflammatory nature of $\mathrm{CPB}$ all contribute to the derangements in systemic and pulmonary vascular resistances, cardiac output, oxygen delivery, and alterations in oxygen demand and metabolism [Figure 1].

Pathologic alterations in cardiac loading conditions are the physiologic basis leading to the low cardiac output state. According to the Frank-Starling mechanism, diminished preload from hypovolemia, inflammation, or elevated filling pressures lead to reduced stroke volume. Respiratory abnormalities from pleural effusions, pneumothorax, or elevated airway pressure from mechanical ventilation have a deleterious effect on ventricular filling. Associated elevations in right ventricular afterload can complicate postoperative patient management, especially in those with right ventricular hypertrophy or dysfunction. Changes in pulmonary vascular resistance (PVR), systemic vascular resistance (SVR) after CPB, and specifically systemic hypertension, can decrease cardiac output after surgery. Furthermore, CPB stimulates vasopressin release, which increases SVR and can be deleterious to a dysfunctional systemic ventricle all leading to LCOS.

The exposure of blood to foreign antigens during CPB, along with hypothermia, myocardial ischemia, and reperfusion injury, can cause profound systemic inflammation ${ }^{[2,3]}$. Specifically, there are elevations in proinflammatory cytokines and activation of complement ${ }^{[4]}$. These are all associated with LCOS, increased ventilator time, and adverse neurologic outcomes ${ }^{[5,6]}$. In addition, there is also a hypermetabolic and catabolic state after surgery driving increased oxygen demand. Detailed reviews of the pathophysiology of LCOS have recently been well described by Epting et al. ${ }^{[7]}$ and Bautista-Hernandez et al ${ }^{[8]}$.

\section{Incidence}

Parr and colleagues first described LCOS in 1975 when they observed patients with a cardiac index less than $2 \mathrm{~L} / \mathrm{min} / \mathrm{m}^{2}$ in approximately $25 \%$ of patients after congenital heart surgery requiring $\mathrm{CPB}^{[9]}$. In the decades to follow, similar estimates of LCOS incidence in children were obtained by Wernovsky et al. ${ }^{[10]}$ and Hoffman et al. ${ }^{[11]}$. However, a more recent study by Du et al. ${ }^{[12]}$ found a LCOS incidence of $\sim 10 \%$ with a contemporary cohort of 8660 children treated at a single center. In this study, independent risk factors for LCOS development included age, CPB time, residual shunts, outflow tract obstruction for either the left ventricle (LV) or right ventricle (RV), and tricuspid and mitral regurgitation. These risk factors and other clinical parameters have been used to develop LCOS scoring systems to assess LCOS severity ${ }^{[13]}$. Therefore, 


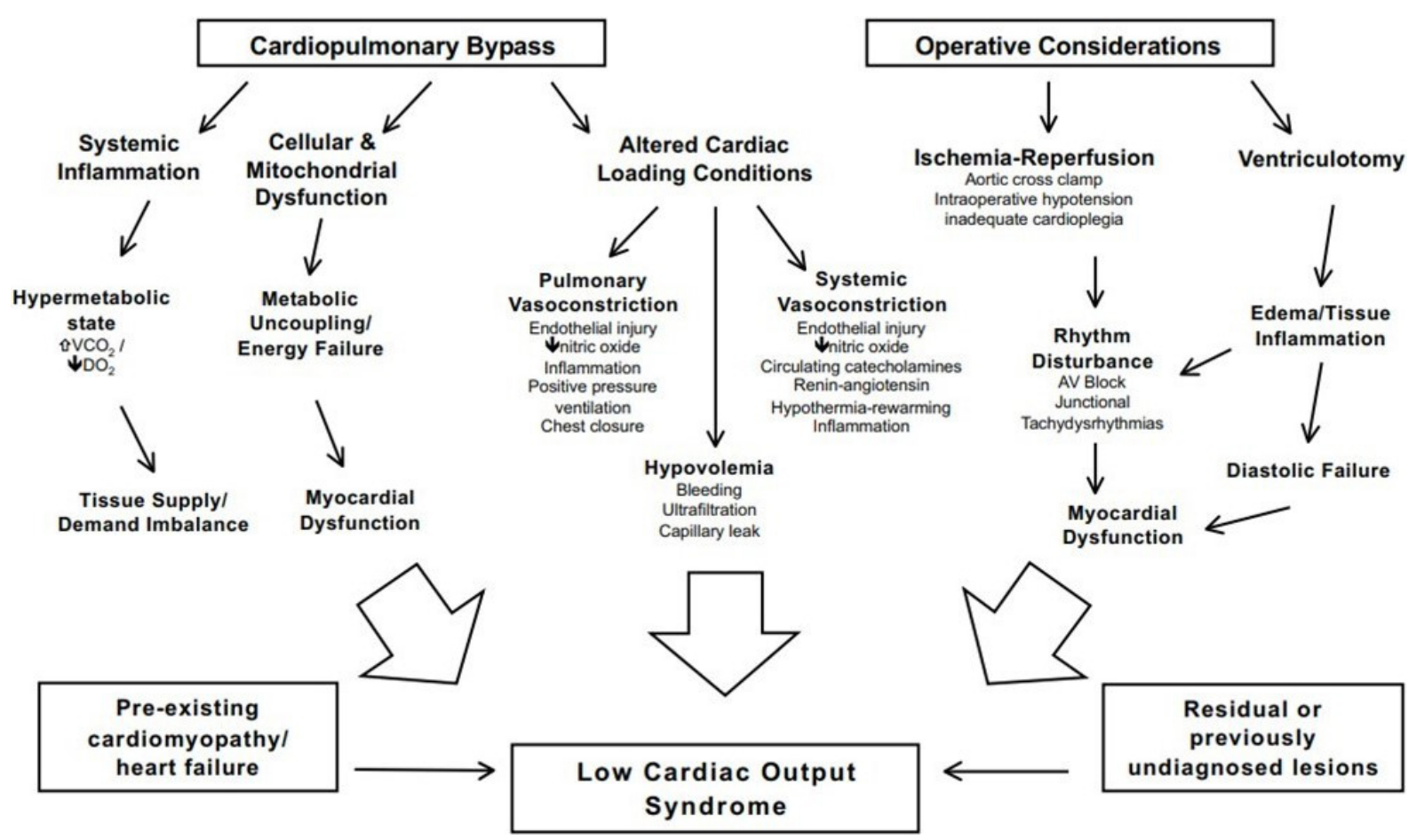

Figure 1. Perioperative factors leading to LCOS. Factors drivern by exposure to CPB (i.e., systemic inflammation, cellular \& mitochondrial dysfunction, altered loading conditions) and those influenced by cardiac surgery (i.e., ischemia, ventriculotomy) are noted schematically contributing to LCOS. Reused with permission from Epting et al. ${ }^{[7]}$ from Bentham Science Pulishers LTD. LCOS: Low cardiac output syndrome; CPB: cardiopulmonary bypass.

it is important to recognize and treat LCOS, as treatment may mitigate the associated morbidity and mortality after cardiac surgery ${ }^{[9]}$. Increased severity of LCOS has been specifically associated with increased duration of mechanical ventilation, intensive care unit (ICU) length of stay (LOS), and hospital LOS ${ }^{[13]}$.

\section{THERAPEUTIC OPTIONS FOR THE LOW CARDIAC OUTPUT SYNDROME}

The fundamental principle guiding the management of LCOS is the maintenance of an appropriate balance between tissue oxygen delivery and demand. There exists a wide range of both invasive and non-invasive methods of monitoring patients for the development of LCOS and oxygen debt, and a detailed description is outside the scope of this article. However, once recognized, the general approach to LCOS management includes using means to increase oxygen delivery while reducing oxygen demand [Figure 2]. The pharmacologic augmentation of cardiac output is the most common method to improve oxygen delivery. Therapeutic agents that increase heart rate, improve contractility, or decrease afterload are commonly used. Optimizing preload to the heart is often the first-line approach, utilizing the Frank-Starling mechanism to improve stroke volume and cardiac output. Furthermore, maintaining atrioventricular synchrony and augmenting heart rate, either by pharmacologic therapies or temporary pacing, can also increase cardiac output and oxygen delivery. Normorthermia, mechanical ventilation, and sedation, with or without neuromuscular blockade, are common means in which to minimize patient effort and decrease oxygen demands. Although many simultaneous methods to manage LCOS are often deployed, we will summarize the evidence that supports the use of certain pharmacologic therapies and review trends in their utilization in the management of LCOS. 


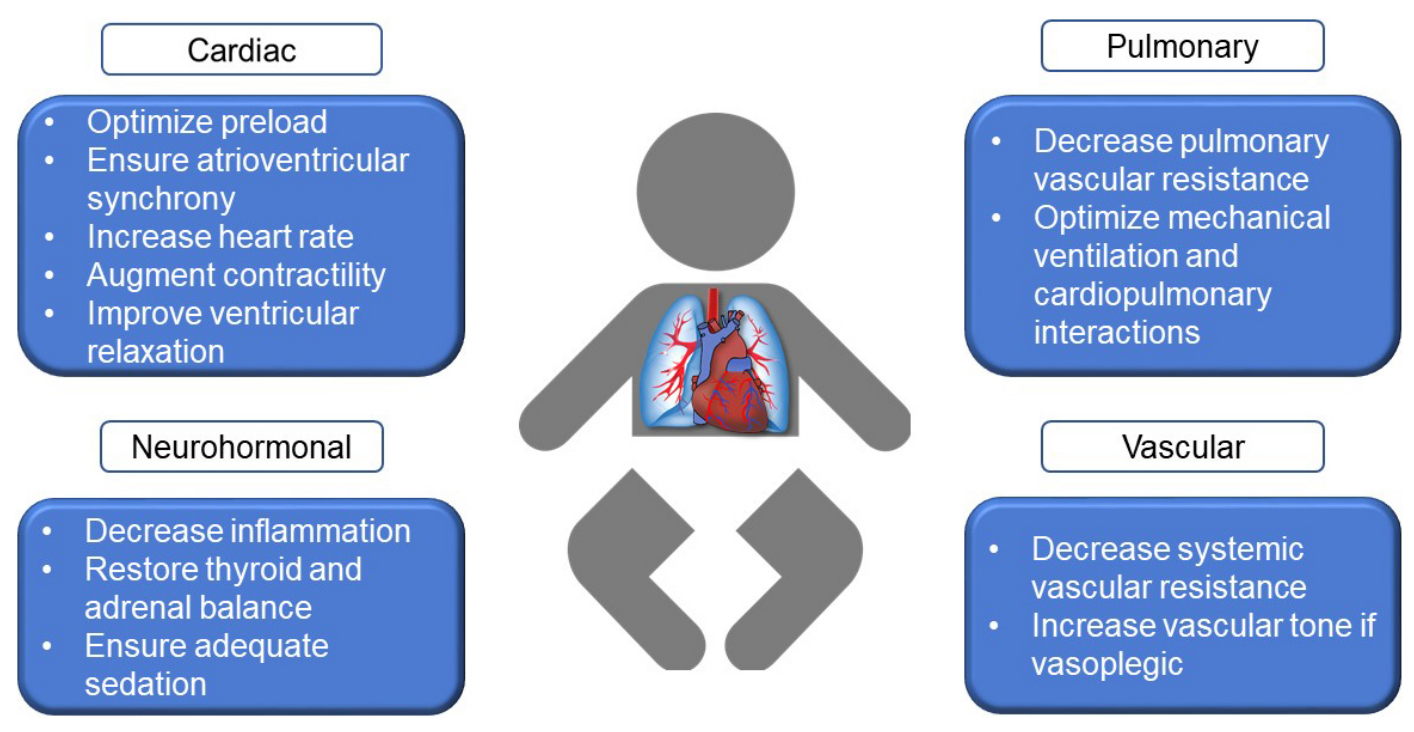

Figure 2. Management strategies for the treatment of low cardiac output syndrome.

\section{Catecholaminergic inotropes}

Catecholaminergic inotropes such as epinephrine, dopamine, and dobutamine have long been used in the cardiac intensive care unit as pharmacologic means to manage LCOS by augmenting cardiac output. They predominantly activate $\beta-1, \beta-2, \alpha-1$, and dopaminergic receptors. $\beta-1$ stimulation increases contractility through the binding of the actin-myosin complex with troponin $C$ and enhances chronotropy through calcium channel activation. $\beta-2$ stimulation leads to increased calcium uptake by the sarcoplasmic reticulum leading to vasodilation. Activation of $\alpha-1$ receptors on arterial vasculature results in smooth muscle contraction and increases in SVR. The relative affinity of the different catecholamines for the adrenergic receptors are dose-dependent, vary from drug to drug, and thus are employed to meet specific physiologic goals. In general, these agents increase contractility and stroke volume and are widely available. However, the adverse effects of catecholamines are relatively universal in their resultant tachycardia, raised ventricular end-diastolic pressures, and increased myocardial oxygen demand. Furthermore, the elevation of the SVR, PVR, or provocation of tachyarrhythmias by these agents can inadvertently cause or exacerbate LCOS. In a recent survey of cardiac intensivists, epinephrine and dopamine were the most common agents in this class used to prevent or treat LCOS, and these medications are most commonly started while on or coming off $\mathrm{CPB}^{[14]}$. However, in a recent Pediatric Health Information System (PHIS) database review of over 43,000 cardiac surgeries in children, the frequency of use of catecholaminergic inotropes has decreased in the past ten years ${ }^{[15]}$. This is likely due to our better understanding of LCOS and the more recent emphasis on reducing RV and LV afterload as alternative means to improve oxygen delivery.

\section{Inodilators}

Inodilators are medications that have inotropic and lusitropic effects on the myocardium and vasodilatory effects on the systemic, pulmonary, and coronary vasculature. Milrinone and levosimendan are the most commonly used medications in this category. Levosimendan, a calcium sensitizer, binds troponin C, increasing its affinity for calcium and increases inotropy without increasing myocardial oxygen demand. Its effects are independent of $\beta$-adrenergic receptors, and thus its use has a minimal incidence of arrhythmias. The most commonly reported side effects are headache, hypotension, and hypokalemia. The efficacy and safety of levosimendan are well reported in adults, but the pediatric literature is sparse and is limited to observational studies, registry studies, and few randomized control trials (RCT). In a study of 40 infants undergoing surgery with $\mathrm{CPB}$ managed with either levosimendan or milrinone, Lechner et al. ${ }^{[16]}$ 
demonstrated that the levosimendan group had improvements in cardiac output and cardiac index. However, inotropic score, lactate levels, and ICU LOS were unchanged between groups. Using postoperative lactate as a surrogate marker of cardiac output, Momeni et al. ${ }^{[17]}$ describe equal efficacy of milrinone and levosimendan in a cohort of 41 children following cardiac surgery; however, because of the high cost and lack of Food and Drug Association approval, levosimendan is not at this time widely used for the management of LCOS in the United States ${ }^{[14]}$.

Milrinone has been studied extensively in children after surgery requiring CPB. Milrinone inhibits phosphodiesterase type 3 leading to an increasing concentration of intracellular cAMP, resulting in increased myocardial contractility. It also accelerates the removal of calcium from the cytosol, allowing more time for myocardial relaxation, thus its lusitropic effect. In addition, its effect on cGMP in the peripheral and coronary smooth muscle cells leads to smooth muscle vasodilation. These simultaneous changes improve myocardial performance without increasing myocardial oxygen demand, and thus milrinone has many advantageous properties. Many studies have reported the positive hemodynamic effects of milrinone in children after cardiac surgery. Most importantly, in the double-blind, placebo-controlled RCT PRIMACORP study, Hoffman et al. ${ }^{[11]}$ demonstrated that high dose milrinone significantly reduced LCOS incidence without increases in adverse events. Since that landmark study, milrinone has become a widely used pharmacologic agent to prevent and treat LCOS in children. However, a 2015 Cochrane review concluded there was insufficient evidence of the effectiveness of prophylactic milrinone in preventing death or LCOS in children undergoing surgery for congenital heart disease ${ }^{[18]}$. Nonetheless, in a recent Pediatric Cardiac Intensive Care Society (PCICS) provider survey, 97\% of respondents stated their center routinely uses milrinone to prevent or treat LCOS after $\mathrm{CPB}^{[14]}$.

\section{Systemic vasodilators}

The purpose of using systemic vasodilators in managing LCOS is to increase stroke volume, cardiac output, and delivery of oxygen to the tissues while decreasing myocardial oxygen demand. Several medications in this class have been trialed in the treatment of LCOS, including systemic nitric oxide donors, natriuretic peptides, and $\alpha$-antagonists. Sodium nitroprusside releases nitric oxide from vascular endothelial cells leading to systemic vasodilation. Appelbaum et al. ${ }^{[19]}$ first described the use of nitroprusside after cardiac surgery and found a $17 \%$ increase in cardiac index. Similarly, the nitro-vasodilator nitroglycerine activates cGMP leading to vasodilation of the systemic arterioles and venules. However, due to its preferential effects on the venodilatory properties, it has been found to be less effective in vasodilation compared to nitroprusside ${ }^{[20]}$. The selective calcium channel blocker nicardipine has also been found to be safe and effective when treating postoperative systemic hypertension, even in children $<6$ months of age ${ }^{[21]}$. Nesiritide, a recombinant form of brain natriuretic peptide, induces smooth muscle relaxation and mitigates the effect of vasopression, leading to vasodilation and promoting diuresis. Although initial adult studies of nesiritide use were associated with improved outcomes after cardiac surgery, subsequent more robust studies and a pooled analysis of RCTs failed to do $\mathrm{so}^{[22-24]}$. Phenoxybenzamine has also been used to block $\alpha-1$ and $\alpha-2$ receptors, relax the smooth muscle of systemic vasculature and increase cardiac output. Tweddell et al. ${ }^{[25]}$ demonstrated an association between improved mortality and the use of phenoxybenzamine in infants with hypoplastic left heart syndrome after stage 1 palliation, thought to be attributed to reduced SVR, reduced fluctuation in systemic venous and arterial saturation, and improved balance of pulmonary to systemic ratio and delivery of oxygen. However, according to an international survey by Roeleveld and de Klerk ${ }^{[14]}$, pure systemic vasodilators are not often used as first-line therapy for LCOS, except for patients with single ventricle circulation, where nitroprusside is the most commonly used agent. 


\section{Pulmonary vasodilators}

Increases in PVR after CPB are one of the pathophysiologic mechanisms believed to contribute to LCOS development, and children with preoperative left-sided obstructive lesions and those with left to right shunts are at higher risk of elevated PVR following bypass. Cardiopulmonary bypass causes inflammation that inhibits nitric oxide production and increases the production of endothelin-1. Thus, inhaled nitric oxide (iNO) and its precursors have been trialed to treat or prevent LCOS. Inhaled nitric oxide is a selective pulmonary vasodilator with little effect on the systemic vasculature. Miller et al. ${ }^{[26]}$ performed a prospective, double-blind RCT of iNO in 124 infants at risk for pulmonary hypertension (PH) and found that iNO reduced indexed PVR, number of $\mathrm{PH}$ crises, and proportion of patients mechanically ventilated at 7 days. In addition, a recent RCT of prophylactic iNO demonstrated a reduction in the incidence of LCOS and the need for ECMO, most markedly seen in children $<2$ years of age, and after highly complex surgeries ${ }^{[27]}$. Another pulmonary vasodilator, the aerosolized prostacyclin iloprost, and iNO were found to be comparable in increasing cardiac output and decreasing pulmonary artery pressures ${ }^{[28]}$. However, in a study by Wong et al. ${ }^{[29]}$ reviewing the PHIS database, of 1678 surgeries performed on patients with known PH, iNO was used only $11.6 \%$ of the time, and its use was associated with increased cost and LOS, with no improvement in mortality. Citrulline, a precursor to nitric oxide, has also been trialed to reduce LCOS incidence and improve outcomes but has not been shown to decrease PH episodes significantly ${ }^{[30]}$. Other inhaled agents such as sildenafil, milrinone, and prostaglandin have also been used for $\mathrm{PH}$ but less frequently for LCOS. At this time, there is insufficient data to support the routine use of pulmonary vasodilators such as iNO, as a Cochrane systematic review did not find differences in mortality or many secondary outcomes with its use ${ }^{[31]}$. However, to better investigate the utility of iNO to increase survival and ventilator-free days after $\mathrm{CPB}$, the multicenter, randomized, double-blind NITric trial is currently underway ${ }^{[32]}$.

\section{ADJUNCTIVE THERAPIES FOR THE LOW CARDIAC OUTPUT SYNDROME Corticosteroids}

Cardiopulmonary bypass is known to cause an inflammatory cascade that is believed to contribute to LCOS and postoperative morbidity. Hence, anti-inflammatory therapy with corticosteroids has been extensively studied for those undergoing cardiac surgery requiring $\mathrm{CPB}^{[33,34]}$. In addition, several studies have investigated the cellular mechanisms whereby corticosteroid supplementation may be beneficial ${ }^{[34,35]}$. However, a recent meta-analysis of 17 RCTs and 848 pediatric patients by Li et al ${ }^{[36]}$ in 2020 concluded that children receiving corticosteroids did not have a reduction in all-cause mortality compared to controls. They did have a significant reduction in vasoinotropic score but had no significant improvement in other secondary outcomes such as ICU LOS, duration of mechanical ventilation, serum lactate, or incidence of LCOS, among others. A recent two-center RCT also failed to show a significant overall benefit in a mortality-morbidity composite index but did similarly demonstrate a reduction in vasoactive requirements ${ }^{[37]}$. However, despite the results of this recent meta-analysis and several RCTs, a survey of 188 PCICS members from 85 centers found that $94 \%$ of survey respondents reported that they sometimes or always administer corticosteroids for patients with moderate or severe LCOS, with hydrocortisone being the most commonly used agent ${ }^{[38]}$. To better understand the utility of corticosteroids for children undergoing cardiac surgery with $\mathrm{CPB}$, the currently ongoing multicenter, placebo-controlled STRESS trial is investigating the efficacy and safety of methylprednisolone administration and its association with major outcomes, including mortality, morbidity, and ventilator time ${ }^{[39]}$.

\section{Thyroid hormone replacement}

Another class of medication that has been trialed in the management of LCOS over the past few decades is thyroid hormone replacement therapy. It has been shown that triiodothyronine (T3) levels decrease in infants and children after $\mathrm{CPB}^{[40]}$. Given the important role of thyroid hormone in metabolism, it was 
postulated that T3 repletion could improve patient outcomes after cardiac surgery. In a pilot RCT performed by Mackie et al. ${ }^{[41]}$, continuous T3 infusions were associated with a significant reduction in the time to negative fluid balance, without significant increases in cardiac index. In the OTICC RCT of 208 patients under three years of age, the incidence of LCOS was lower in those receiving the oral T3 group compared to placebo ${ }^{[42]}$. The more comprehensive TRICC RCT included 193 children under two years of age undergoing surgery with $\mathrm{CPB}$. Although overall, there was no significant difference in time to extubation between the T3 replacement and placebo groups, subgroup analysis demonstrated improved time to extubation and extubation success rate for children less than five months of age receiving $\mathrm{T}^{[43]}$. Similar improvements with T3 administration in children less than five months of age were found by Marwali et al. ${ }^{[4]}$. However, in a 2019 meta-analysis by Flores et al. ${ }^{[45]}$, although there was a significant reduction in the mean inotropic score for those receiving some form of $\mathrm{T} 3$, there was no difference in any other significant outcomes, including ventilator time, ICU LOS, hospital LOS, or mortality.

\section{Vasopressin and norepinephrine}

Vasopressin and norepinephrine have been used in the management of patients with LCOS and vasoplegia. Although increases in SVR can lead to a decrease in cardiac output, they can be used to maintain adequate perfusion pressures for vital organs such as the brain and kidneys. The use of arginine vasopressin, the stimulant of the $\mathrm{V} 1$ receptor, has been shown to decrease the need for fluid resuscitation and inotropic support. However, it has not been found to be associated with significant improvements in major outcomes like ICU LOS or duration of mechanical ventilation ${ }^{[46]}$. Interestingly, for patients undergoing the Fontan procedure, transpulmonary gradient and chest tube drainage were significantly lower in the vasopressin group compared to placebo ${ }^{[47]}$. Norepinephrine has been used for patients with LCOS and low systemic vascular resistance, but less commonly than epinephrine and vasopressin ${ }^{[48]}$. Finally, in a recent review of the PHIS database by Loomba and Flores ${ }^{[15]}$, while the use of catecholaminergic inotropes and vasopressors after cardiac surgery have decreased over the past ten years, the use of vasopressin has increased.

\section{Extracorporeal life support}

There is, unfortunately, a subpopulation of children who experience prolonged or severe LCOS refractory to medical management who may require short or long-term mechanical circulatory support (MCS). Early recognition of the failure of medical management for LCOS is important so that MCS can more safely be deployed prior to cardiac arrest. Extracorporeal membrane oxygenation is a commonly used and widely available therapy for prolonged or medically refractory $\operatorname{LCOS}^{[49]}$. A 2014 analysis of the Society for Thoracic Surgeons database found that $2.4 \%$ of all surgical patients are placed on postoperative MCS, and $95 \%$ of the cases utilized extracorporeal membrane oxygenation as the MCS strategy ${ }^{[50]}$. Unfortunately for those needing postoperative MCS, the mortality remains dauntingly high, with rates up to $\sim 65 \%^{[51]}$.

\section{CONCLUSION}

The management of low cardiac output syndrome after pediatric cardiac surgery is evolving, and new pharmacologic therapies continue to emerge with ongoing research. At this time, there is insufficient evidence to support a single pharmacologic agent as the universal best therapy for the prevention or treatment of low cardiac output syndrome. Database reviews and surveys demonstrate that milrinone, epinephrine, and dopamine are the most commonly used pharmacologic therapies, but there remains substantial provider and center variability in the approach towards the management of these patients. Therefore, rigorous multicenter studies with granular data are needed to help providers tailor specific pharmacologic therapies to best support each critically ill child. 


\title{
DECLARATIONS
}

\section{Authors' contributions}

Contributed to the creation, authorship, review and approval of this article: Sahulee R, McKinstry J

\author{
Availability of data and materials \\ Not applicable.
}

\section{Financial support and sponsorship}

None.

\section{Conflicts of interest}

Both authors declared that there are no conflicts of interest.

\author{
Ethical approval and consent to participate \\ Not applicable.
}

\section{Consent for publication}

The authors consent to the publication of this material.

\section{Copyright}

(c) The Author(s) 2022.

\section{REFERENCES}

1. Wessel DL. Managing low cardiac output syndrome after congenital heart surgery. Crit Care Med 2001;29:S220-30. DOI PubMed

2. Gabay C, Kushner I. Acute-phase proteins and other systemic responses to inflammation. N Engl J Med 1999;340:448-54. DOI PubMed

3. Kozik DJ, Tweddell JS. Characterizing the inflammatory response to cardiopulmonary bypass in children. Ann Thorac Surg 2006;81:S2347-54. DOI PubMed

4. Aĝirbaşli M, Nguyen ML, Win K, et al. Inflammatory and hemostatic response to cardiopulmonary bypass in pediatric population: feasibility of seriological testing of multiple biomarkers. Artif Organs 2010;34:987-95. DOI PubMed

5. Mcguinness J, Bouchier-hayes D, Redmond J. Understanding the inflammatory response to cardiac surgery. Surgeon 2008;6:162-71. DOI PubMed

6. Ramaswamy V, Horton J, Vandermeer B, Buscemi N, Miller S, Yager J. Systematic review of biomarkers of brain injury in term neonatal encephalopathy. Pediatr Neurol 2009;40:215-26. DOI PubMed

7. Epting CL, McBride ME, Wald EL, Costello JM. Pathophysiology of post-operative low cardiac output syndrome. Curr Vasc Pharmacol 2016;14:14-23. DOI PubMed

8. Bautista-Hernandez V, Karamanlidis G, McCully JD, Del Nido PJ. Cellular and molecular mechanisms of low cardiac output syndrome after pediatric cardiac surgery. Curr Vasc Pharmacol 2016;14:5-13. DOI PubMed

9. Parr GV, Blackstone EH, Kirklin JW. Cardiac performance and mortality early after intracardiac surgery in infants and young children. Circulation 1975;51:867-74. DOI PubMed

10. Wernovsky G, Wypij D, Jonas RA, et al. Postoperative course and hemodynamic profile after the arterial switch operation in neonates and infants. A comparison of low-flow cardiopulmonary bypass and circulatory arrest. Circulation 1995;92:2226-35. DOI PubMed

11. Hoffman TM, Wernovsky G, Atz AM, et al. Efficacy and safety of milrinone in preventing low cardiac output syndrome in infants and children after corrective surgery for congenital heart disease. Circulation 2003;107:996-1002. DOI PubMed

12. Du X, Chen H, Song X, et al. Risk factors for low cardiac output syndrome in children with congenital heart disease undergoing cardiac surgery: a retrospective cohort study. BMC Pediatr 2020;20:87. DOI PubMed PMC

13. Ulate KP, Yanay O, Jeffries H, Baden H, Di Gennaro JL, Zimmerman J. An elevated low cardiac output syndrome score is associated with morbidity in infants after congenital heart surgery. Pediatr Crit Care Med 2017;18:26-33. DOI PubMed

14. Roeleveld PP, de Klerk JCA. The perspective of the intensivist on inotropes and postoperative care following pediatric heart surgery: an international survey and systematic review of the literature. World J Pediatr Congenit Heart Surg 2018;9:10-21. DOI PubMed PMC

15. Loomba RS, Flores S. Use of vasoactive agents in postoperative pediatric cardiac patients: insights from a national database. Congenit Heart Dis 2019;14:1176-84. DOI PubMed

16. Lechner E, Hofer A, Leitner-Peneder G, et al. Levosimendan versus milrinone in neonates and infants after corrective open-heart surgery: a pilot study. Pediatr Crit Care Med 2012;13:542-8. DOI PubMed

17. Momeni M, Rubay J, Matta A, et al. Levosimendan in congenital cardiac surgery: a randomized, double-blind clinical trial. $J$ 
Cardiothorac Vasc Anesth 2011;25:419-24. DOI PubMed

18. Burkhardt BE, Rücker G, Stiller B. Prophylactic milrinone for the prevention of low cardiac output syndrome and mortality in children undergoing surgery for congenital heart disease. Cochrane Database Syst Rev 2015;3:CD009515. DOI PubMed

19. Appelbaum A, Blackstone EH, Kouchoukos NT, Kirklin JW. Afterload reduction and cardiac output in infants early after intracardiac surgery. Am J Cardiol 1977;39:445-51. DOI PubMed

20. Ranadive SM, Eugene AR, Dillon G, Nicholson WT, Joyner MJ. Comparison of the vasodilatory effects of sodium nitroprusside vs. nitroglycerin. J Appl Physiol (1985) 2017;123:402-6. DOI PubMed PMC

21. Stone ML, Kelly J, Mistry M, Buck M, Gangemi J, Vergales J. Use of nicardipine after cardiac operations is safe in children regardless of age. Ann Thorac Surg 2018;105:181-5. DOI PubMed

22. Colucci WS, Elkayam U, Horton DP, et al. Intravenous nesiritide, a natriuretic peptide, in the treatment of decompensated congestive heart failure. Nesiritide Study Group. N Engl J Med 2000;343:246-53. DOI PubMed

23. Publication Committee for the VMAC Investigators (Vasodilatation in the Management of Acute CHF). Intravenous nesiritide vs nitroglycerin for treatment of decompensated congestive heart failure: a randomized controlled trial. JAMA 2002;287:1531-40. DOI PubMed

24. Sackner-Bernstein JD, Kowalski M, Fox M, Aaronson K. Short-term risk of death after treatment with nesiritide for decompensated heart failure: a pooled analysis of randomized controlled trials. JAMA 2005;293:1900-5. DOI PubMed

25. Tweddell JS, Hoffman GM, Mussatto KA, et al. Improved survival of patients undergoing palliation of hypoplastic left heart syndrome: lessons learned from 115 consecutive patients. Circulation 2002;106:I82-9. PubMed

26. Miller OI, Tang SF, Keech A, Pigott NB, Beller E, Celermajer DS. Inhaled nitric oxide and prevention of pulmonary hypertension after congenital heart surgery: a randomised double-blind study. Lancet 2000;356:1464-9. DOI PubMed

27. James C, Millar J, Horton S, Brizard C, Molesworth C, Butt W. Nitric oxide administration during paediatric cardiopulmonary bypass: a randomised controlled trial. Intensive Care Med 2016;42:1744-52. DOI PubMed

28. Kirbas A, Yalcin Y, Tanrikulu N, Gürer O, Isik O. Comparison of inhaled nitric oxide and aerosolized iloprost in pulmonary hypertension in children with congenital heart surgery. Cardiol $J$ 2012;19:387-94. DOI PubMed

29. Wong J, Loomba RS, Evey L, Bronicki RA, Flores S. Postoperative inhaled nitric oxide does not decrease length of stay in pediatric cardiac surgery admissions. Pediatr Cardiol 2019;40:1559-68. DOI PubMed

30. Smith HA, Canter JA, Christian KG, et al. Nitric oxide precursors and congenital heart surgery: a randomized controlled trial of oral citrulline. J Thorac Cardiovasc Surg 2006;132:58-65. DOI PubMed

31. Bizzarro M, Gross I, Barbosa FT. Inhaled nitric oxide for the postoperative management of pulmonary hypertension in infants and children with congenital heart disease. Cochrane Database Syst Rev 2014:CD005055. DOI PubMed

32. Schlapbach LJ, Horton SB, Long DA, et al; NITRIC Study Group, the Australian and New Zealand Intensive Care Society Clinical Trials Group (ANZICS CTG), the Paediatric Critical Care Research group (PCCRG) and the ANZICS Paediatric Study Group (PSG). Study protocol: NITric oxide during cardiopulmonary bypass to improve Recovery in Infants with Congenital heart defects (NITRIC trial): a randomised controlled trial. BMJ Open 2019;9:e026664. DOI PubMed PMC

33. Graham EM, Atz AM, Butts RJ, et al. Standardized preoperative corticosteroid treatment in neonates undergoing cardiac surgery: results from a randomized trial. $J$ Thorac Cardiovasc Surg 2011;142:1523-9. DOI PubMed PMC

34. Shore S, Nelson DP, Pearl JM, et al. Usefulness of corticosteroid therapy in decreasing epinephrine requirements in critically ill infants with congenital heart disease. Am J Cardiol 2001;88:591-4. DOI PubMed

35. Hall RI, Smith MS, Rocker G. The systemic inflammatory response to cardiopulmonary bypass: pathophysiological, therapeutic, and pharmacological considerations. Anesth Analg 1997;85:766-82. DOI PubMed

36. Li Y, Luo Q, Wu X, Jia Y, Yan F. Perioperative corticosteroid therapy in children undergoing cardiac surgery: a systematic review and meta-analysis. Front Pediatr 2020;8:350. DOI PubMed PMC

37. Graham EM, Martin RH, Buckley JR, et al. Corticosteroid therapy in neonates undergoing cardiopulmonary bypass: randomized controlled trial. J Am Coll Cardiol 2019;74:659-68. DOI PubMed PMC

38. Flores S, FitzGerald MR, Iliopoulos I, et al. An international survey of corticosteroid use for the management of low cardiac output syndrome. Pediatr Crit Care Med 2017;18:630-7. DOI PubMed PMC

39. Hill KD, Baldwin HS, Bichel DP, et al; STRESS Network Investigators. Rationale and design of the STeroids to REduce Systemic inflammation after infant heart Surgery (STRESS) trial. Am Heart J 2020;220:192-202. DOI PubMed PMC

40. Bettendorf M, Schmidt KG, Tiefenbacher U, Grulich-Henn J, Heinrich UE, Schönberg DK. Transient secondary hypothyroidism in children after cardiac surgery. Pediatr Res 1997;41:375-9. DOI PubMed

41. Mackie AS, Booth KL, Newburger JW, et al. A randomized, double-blind, placebo-controlled pilot trial of triiodothyronine in neonatal heart surgery. J Thorac Cardiovasc Surg 2005;130:810-6. DOI PubMed

42. Marwali EM, Caesa P, Darmaputri S, et al. Oral Triiodothyronine supplementation decreases low cardiac output syndrome after pediatric cardiac surgery. Pediatr Cardiol 2019;40:1238-46. DOI PubMed

43. Portman MA, Slee A, Olson AK, et al; TRICC Investigators. Triiodothyronine supplementation in infants and children undergoing cardiopulmonary bypass (TRICC): a multicenter placebo-controlled randomized trial: age analysis. Circulation 2010;122:S224-33. DOI PubMed PMC

44. Marwali EM, Boom CE, Budiwardhana N, et al. Oral triiodothyronine for infants and children undergoing cardiopulmonary bypass. Ann Thorac Surg 2017;104:688-95. DOI PubMed

45. Flores S, Loomba RS, Checchia PA, Graham EM, Bronicki RA. Thyroid hormone (triiodothyronine) therapy in children after congenital heart surgery: a meta-analysis. Semin Thorac Cardiovasc Surg 2020;32:87-95. DOI PubMed 
46. Alten JA, Borasino S, Toms R, Law MA, Moellinger A, Dabal RJ. Early initiation of arginine vasopressin infusion in neonates after complex cardiac surgery. Pediatr Crit Care Med 2012;13:300-4. DOI PubMed

47. Bigelow AM, Ghanayem NS, Thompson NE, et al. Safety and efficacy of vasopressin after fontan completion: a randomized pilot study. Ann Thorac Surg 2019;108:1865-74. DOI PubMed

48. Rizza A, Bignami E, Belletti A, et al. Vasoactive Drugs and hemodynamic monitoring in pediatric cardiac intensive care: an italian survey. World J Pediatr Congenit Heart Surg 2016;7:25-31. DOI PubMed

49. Yuerek M, Rossano JW, Mascio CE, Shaddy RE. Postoperative management of heart failure in pediatric patients. Expert Rev Cardiovasc Ther 2016;14:201-15. DOI PubMed

50. Mascio CE, Austin EH 3rd, Jacobs JP, et al. Perioperative mechanical circulatory support in children: an analysis of the Society of Thoracic Surgeons Congenital Heart Surgery Database. J Thorac Cardiovasc Surg 2014;147:658-64: discussion 664-5. DOI PubMed PMC

51. Coskun KO, Popov AF, Coskun ST, et al. Extracorporeal life support in pediatric patients with congenital heart diseases: outcome of a single centre. Minerva Pediatr 2010;62:233-8. PubMed 